\title{
Study on The Role of Crumb Rubber on The Thermal and Mechanical Properties of Natural Rubber Nanocomposites
}

\author{
B. K. Saleh ${ }^{1}$ and M. H. Khalii ${ }^{2}$ \\ ${ }^{1}$ Polymer Department, National Institute for Standards, Giza.Egypt. \\ ${ }^{2}$ Heat and Moisture Department, building Physics Institute, Housing and Building \\ National Research Center, Cairo, Egypt.
}

\begin{abstract}
CRUMB rubber represents a series hazardous waste that causes environmental pollution that needs to be treated. Such a problem consumes a high budget in controlling its consequences. The main objective of this study is to get maximum benefit from this waste and use it as a filler in green processing to obtain useful materials such as heat insulators. Thus, the black filler was removed from the natural rubber mixes and crumb rubber from waste in different ratios was used instead to form rubber composite that contains a small amount of organo modified nanoclay to maintain the mechanical properties of the vulcanized rubber composites. A controlling mix containing black carbon filler was used to compare the obtained results from crumb/NR nanocomposites. These mixes were examined by Scanning Electron Microscopy (SEM) and the graphs revealed that at higher ratios of crumb rubber in the mix, crumb forms a dispersible network within the rubber blend matrix which enhances the miscibility between the rubber and all other ingredients. TGA data indicated high thermal stability of all crumb/NR nanocomposites. All results showed that the addition of crumb to natural rubber nanocomposites enhanced the levels of the properties especially for the mix of the ratio 4:6 for crumb: natural rubber. Results of thermal conductivity measurements assured that such mix acts as an insulating material and may be used in constructural applications for shielding purposes.
\end{abstract}

Keywords: Crumb rubber, Filler, Natural rubber, Nanocomposites, Green processing, Constructural applications.

\section{Introduction}

Crumb rubber, scrape rubber, end-of-life tires and waste rubber are all synonyms to used tires. Used tires are tires that have completed their functional life and cannot be used again. It has been estimated that around one billion tires are withdrawn from use in the world every year. Being made from vulcanized rubbers which do not decompose easily, represent a crucial environmental debate. Usually, they are buried with other industrial waste in landfill sites or stockpiled in huge dumps built of millions of tires. Recycling of waste tire was found to be a hard challenge to achieve without causing more environmental pollution problems in the mean time [1]. Scientific efforts directed to this field for finding ways to reduce tires waste lead to intense research on rubber, the possibility of applying it in concrete[1], filler in natural rubber vulcanizates, and blends with polymers [2-7]. Regarding the recovery of crumb, it includes reuse, rethreading, recycling and landfill engineering. Sometimes, in order to achieve the suitable characteristics for its application, rubber needs to be pre-treated with chemicals or grafted $[8,9]$. This may include reclaiming, oxidative decoupling of rubber scrap [10], the use of microwave [11] and combination of biological and microwave treatment [12]. Preparation of thermoplastics elastomers (TPEs) is a promising alternative to utilize crumb rubber namely called waste tire dust (WTD), is blended with thermoplastics such as ethylene vinly acetate (EVA) producing (TPEs) with a range of properties and applications. Besides having

\footnotetext{
* Corresponding author e-mail:basmasalehnis@yahoo.com.

DOI: 10.21608/ejchem.2017.1376.1097

C2017 National Information and Documentation Centre (NIDOC)
} 
physical properties of both, thermoplastics and elastomer and processability similar to that of thermoplastics; TPEs provides better utilization of such waste. Replacement of TPEs original components crumb rubber is very valuable from economical and ecological standpoints [13-18]. Unfortunately, the introduction of WTD into rubber recipes of polyolefin/rubber significantly lowered the mechanical properties because of the poor interfacial adhesion between the blend ingredients. This problem can be solved by different modification techniques. Such techniques include particle size reduction of WTD, varying compatibilizing techniques, oxidation treatments on the WTD surface of waste rubber and exposure to gamma radiation [21]. Results of gamma radiation pre-treatment of WTD showed the enhancement of the mechanical properties of WTD/rubber blend. This is because gamma radiation helps to break the sulfur cross-links of the crumb rubber previously formed and allows the rubber to regain mobility for better reprocessing and remolding and hence increases the compatibility between the virgin rubber and waste crumb rubber [22,23 ]. It has been found that the mechanical properties of sulfur-cured rubber vulcanizates are highly affected by changes in the cross-link density. For natural rubber (NR), the tensile strength and tear strength improved as a function of the cross-link density, reaching some optimum values and then decreased as the cross-link density was raised further. It is important to note that the further increase in radiation dose resulted in a progressive increase in mechanical properties of WTD/rubber bled and revealed devulcanization [24].

In the present work, crumb was added to natural rubber nanocomposites in different ratios. Thus, crumb acted as a filler and a replacement of both NR and carbon black at the same time. The maximum loading of crumb were then determined and the mechanical and thermal insulation properties was investigated and compared to a control mix that contain the black filler. Also, surface morphology of all examined samples was studied by SEM.

\section{Experimental}

Natural rubber used in this study is SMR-20, supplied by Techopolimeri srl., Russia. This grade has good processing characteristics and physical properties. Its low viscosity and easier mixing characteristics, compared with RSS grades, can considerably reduce the mastication and mixing period. Crumb rubber was obtained from a local

Egypt. J. Chem. 60, No. 6 (2017) factory. Carbon Black was of the High Abrasion HAF-N330 (Iodine Adsorption $80 \mathrm{mg} / \mathrm{g}$ and mean particle size $32 \mathrm{~nm}$ ), Transporting \& Engineering Co., Egypt. Zinc Oxide was supplier by Zinchem., South Africa and Stearic Acid was provided by Palm Olio, Malysia. MBT and TMTD were brought from Transporting \& Engineering Co., Egypt. N-phenyl-N'-(1,3-dimethylbutyl)-p-phenylene diamine (6PPD) was supplied by Crompton, Italy. Sulfur was given by Flexis, Belgium. Nanoclay was of the surface modified that contains 25-30 wt \% methyl dihydroxy ethyl from Sigma-Aldrich Chemistry. All other ingredients were purchased from Transporting \& Engineering Co., Egypt.

\section{Preparation of crumb/NR nanocomposites}

Using a two-roll mill, the crumb/NR compositions were prepared according to ASTM D 3182-07 procedures [25]. Mixes were then prepared using different percent ratios of crumb and NR as presented in Table 1. The natural rubber was firstly masticated and the nanoclay was then added. The crumb was introduced in addition to the other ingredients. Finally, the curative package was then added to the crumb/NR nanocomposites and mixed under the above mentioned procedures.

\section{Rheology Measurements}

The cure characteristics of the rubber mixes, including the cure time, were determined at 152 ${ }^{\circ} \mathrm{C}$ according to the technical procedures (ASTM D 2084-07)[26].

\section{Mechanical Testing}

Stress-strain behavior of rubber materials was examined using a Zwick Tensile Testing Machine Z-010, Germany. For this purpose, samples were prepared and cut from molded sheets into dumb bell shape with the dimensions of $150 \times 150 \times 2$ $\mathrm{mm}$. Tensile strength, Elongation Modulus and Elongation at break percent were measured according to ASTM D 412-15 Procedures [27].

\section{Hardness Testing}

Hardness testing measurements were determined according to ASTM D 2240-05 [28] by using a Zwick Hardness Tester 3150, Germany.

\section{Scanning Electron Microscopy}

This analysis was carried out to study the surface morphology of crumb/NR and nanocomposite layers. The SEM micrographs of surface were examined magnifications using an Inspect S Machine FEI Company, Holland.

\section{Thermal Gravimetric Analysis (TGA)}

Thermal Gravimetric Analysis (TGA) of all crumb/NR nanocomposites studies were carried 
TABLE 1. Rubber formulations and ingredients.

\begin{tabular}{lccccccc}
\hline Mix Symbol & $\mathrm{B}_{\mathrm{R}}$ & $\mathrm{B}_{0 / 10}$ & $\mathrm{~B}_{1 / 9}$ & $\mathrm{~B}_{2 / 8}$ & $\mathrm{~B}_{3 / 7}$ & $\mathrm{~B}_{4 / 6}$ & $\mathrm{~B}_{5 / 5}$ \\
\hline Ingredients & & & & & & & \\
NR & 100 & 90 & 90 & 80 & 70 & 60 & 50 \\
Crumb rubber & --- & 10 & 10 & 20 & 30 & 40 & 50 \\
Nanoclay & 0 & 2.5 & 10 & 10 & 10 & 10 & 10 \\
ZnO & 5 & 5 & 5 & 5 & 5 & 5 & 5 \\
Stearic Acid & 2 & 2 & 2 & 2 & 2 & 2 & 2 \\
6 PPD & 1 & 1 & 1 & 1 & 1 & 1 & 1 \\
MBT & 0.5 & 0.5 & 0.5 & 0.5 & 0.5 & 0.5 & 0.5 \\
TMTD & 1.5 & 1.5 & 1.5 & 1.5 & 1.5 & 1.5 & 1.5 \\
Carbon Black & 60 & 20 & --- & --- & --- & -- & -- \\
Sulfur & 2.5 & 2.5 & 2.5 & 2.5 & 2.5 & 2.5 & 2.5 \\
\hline PPD: N-phenyl-N'-(1,3-dimethylbutyl)-p-phenylene diamine (6PPD), MBT: 2-Mercaptobenzothiazole, TMTD: Tetramethyl thiuram
\end{tabular}

out using Shimadzu-50 Thermogravimetric Analyzer in presence of air at a rate of $10{ }^{\circ} \mathrm{C} /$ min, using temperature range of 25 to $650{ }^{\circ} \mathrm{C}$. Degradation temperature of the composites was studied through this analysis.

\section{Thermal Conductivity}

It measures the ability of a material to conduct heat If is placed between two flat isothermal plates maintained at two different temperatures. As a result, and a uniform one-dimensional temperature field due to the temperature gradient between the two hot and cold plates is created. This temperature gradient can be determined by measurements of the temperature difference between the plates using a laser comp apparatus and following ASTM C 518-15.

\section{Results and Discussion}

\section{Mechanical properties}

The mechanical properties of crumb/natural rubber nanocomposites such as tensile strength, elongation at break E \% and elongation modulus in addition to hardness give a good indication to evaluate the effect of certain additive/ingredient to the rubber mix. Stress-strain curves of all crumb/NR nanocomposites are given in Fig. 1-3 and tabulated in Table 2. Figure 1 describes the effect of increasing the crumb rubber loading on the tensile strength of crumb/NR nanocomposites. The tensile strength starts to increase and reach a maximum value for mix $B_{4 / 6}$ which contains 40 phr crumb and $60 \mathrm{phr}$ of NR. Compared with the control mix, the tensile strength of that mix slightly exceeds that of the control mix. It is worth mentioning that for further increase of crumb in the mix $B_{5 / 5}$ shows a slight decrease in tensile strength to an extent that still approximately equal to the value of the control sample. Similar trends were followed for E \% and Modulus that are being prescribed in Fig. 2 and 3, respectively. This attitude could be explained on the basis that the successive increase in crumb rubber percent is accompanied by a similar increase in the crosslink density that appears as an increase in the mechanical properties with the increase of the crumb percent [30]. Movahed et al mentioned that Mechanical properties of sulfur-cured rubber vulcanizates are affected by the Cross-Link Density of rubber for natural rubber (NR). The tensile strength and tear strength improved as a function of cross-link density, reaching some optimum values and then decreased as the crosslink density was raised further [24]. Also the presence of nanoclay may help in enhancing the compatibility between the crumb and NR and cause leveling up of the mechanical properties of mixes having higher crumb loadings. These results were confirmed on the basis of results obtained by morphology studies.

\section{Hardneass Testing}

The hardness of natural rubber nanocomposites containing different percentages of crumb rubber started to increase at lower levels of crumb and started to show an appreciable increase with Increasing the crumb percent in the mix. The Egypt. J. Chem. 60, No. 6 (2017) 
hardness value reaches its highest level for the nanocomposite enriched with $50 \%$ of crumb as indicated in Fig. 4. The increase in hardness of those crumb/NR nanocomposite samples is probably due to the increase in cross-link density. This is evident by the values of maximum tourque obtained from the rheometric data tabulated in Table 3. The $M_{H}$ values show a marked increase as the crumb rubber percent increases to reach a maximum value for mix $B_{4 / 6} \%$ of crumb rubber. The $M_{H}$ value is an indicator of the crosslink density of the rubber; the higher the $\mathrm{M}_{\mathrm{H}}$ values, the higher the cross-link densities. Therefore, the results indicate higher cross-link densities for mixes having higher crumb rubber percent levels.

\section{Scanning Electronic Microscopy}

The SEM micrographs are shown in Fig. 5. It is clear that the control sample $\left(B_{R}\right)$ showed a smooth surface indicating a complete miscibility of the NR, crumb rubber and all other ingredients. The addition of 10, 20 and 30 percent of crumb rubber leads to a surface roughness as shown in samples $\mathrm{B}_{1 / 9}, \mathrm{~B}_{2 / 8}$ and $\mathrm{B}_{3 / 7}$, respectively. However at higher percent $(40 \%)$ and $(50 \%)$ as shown in samples $\mathrm{B}_{4 / 6}$ and $\mathrm{B}_{5 / 5}$ respectively, the samples surface became smoother indicating a one phase

TABLE 2. Mechanical properties of natural rubber nanocomposites with different crumb rubber loadings.

\begin{tabular}{|c|c|c|c|c|c|}
\hline \multicolumn{2}{|r|}{ Mix } & \multirow{2}{*}{$\begin{array}{c}\text { Tensile Strength }(\mathrm{MPa}) \\
6.18\end{array}$} & \multirow{2}{*}{$\begin{array}{c}\begin{array}{c}\text { E-Modulus } \\
(\mathrm{MPa})\end{array} \\
5.41\end{array}$} & \multirow{2}{*}{$\begin{array}{c}\text { Elongation \% at break } \\
264.27\end{array}$} & \multirow{2}{*}{$\begin{array}{c}\text { Hardness Shore (A) } \\
65.00\end{array}$} \\
\hline B & $\mathrm{R}$ & & & & \\
\hline B & $0 / 10$ & 3.13 & 4.68 & 162.67 & 54.37 \\
\hline B & $1 / 9$ & 4.75 & 5.14 & 227.27 & 58.96 \\
\hline B & $2 / 8$ & 5.60 & 5.19 & 246.24 & 61.02 \\
\hline B & $3 / 7$ & 5.75 & 5.30 & 287.43 & 62.24 \\
\hline B & $4 / 6$ & 6.47 & 5.68 & 313.23 & 67.22 \\
\hline B & $5 / 5$ & 5.82 & 5.46 & 264.27 & 64.40 \\
\hline
\end{tabular}

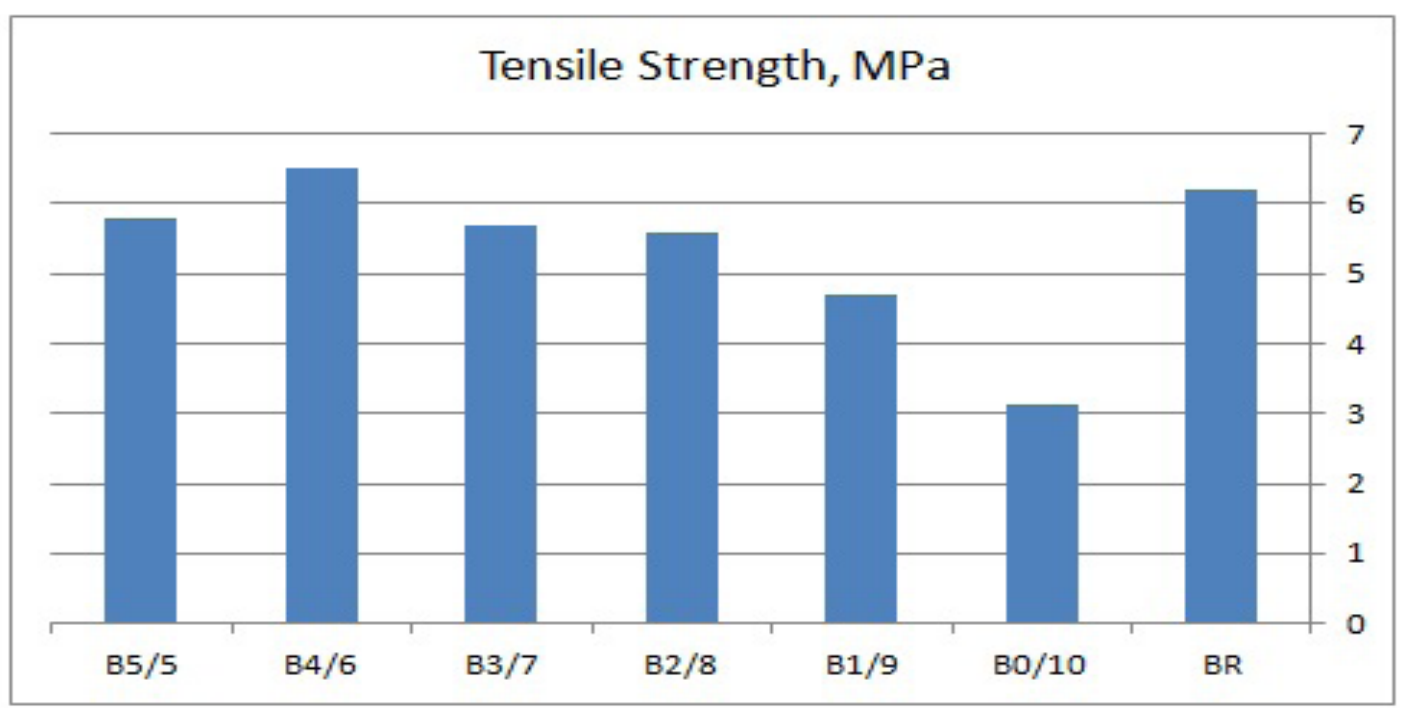

Fig. 1. Tensile strength of natural rubber nanocomposites vs. different crumb rubber loadings. 


\section{Elongation at break, \%}



Fig. 2. Elongation at break \% vs. the percent of crumb rubber of natural nancomposites

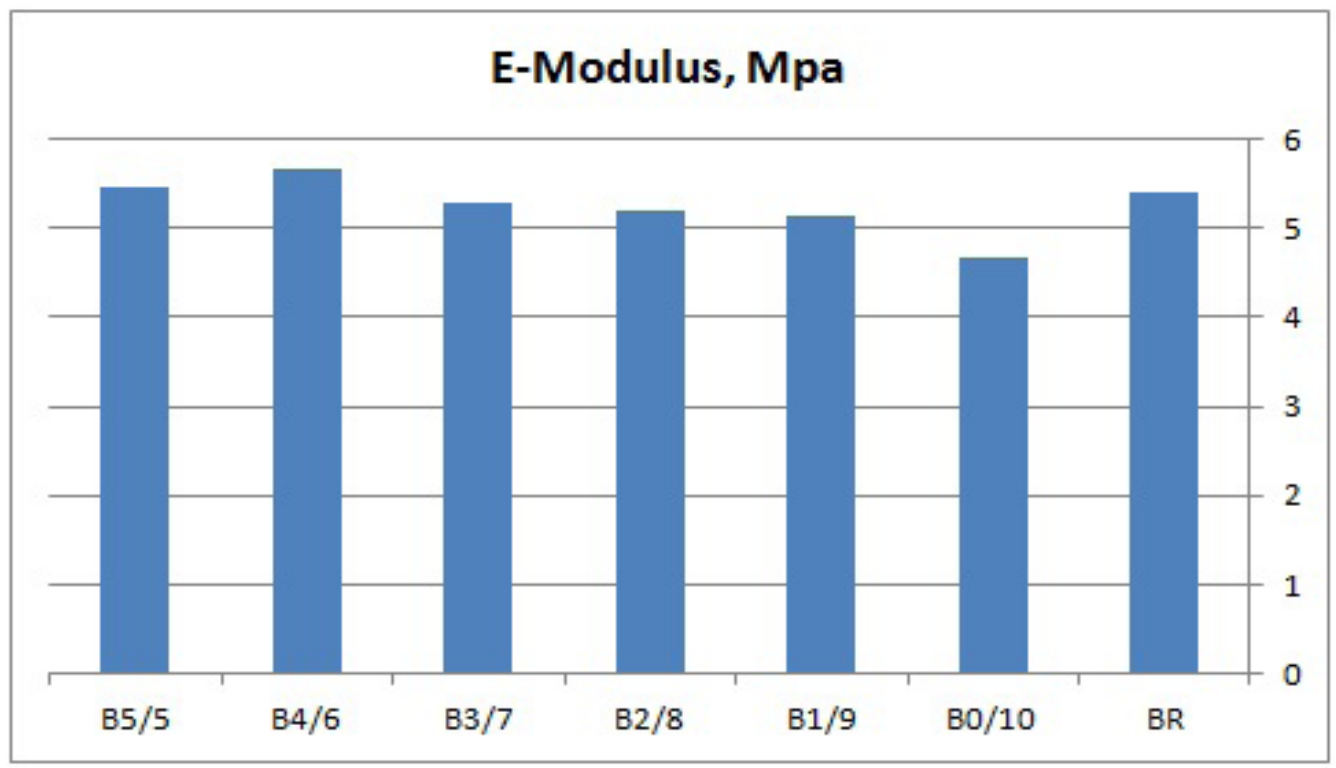

Fig. 3. E-Modulus vs. crumb rubber percent of natural rubber nanocomposites. 


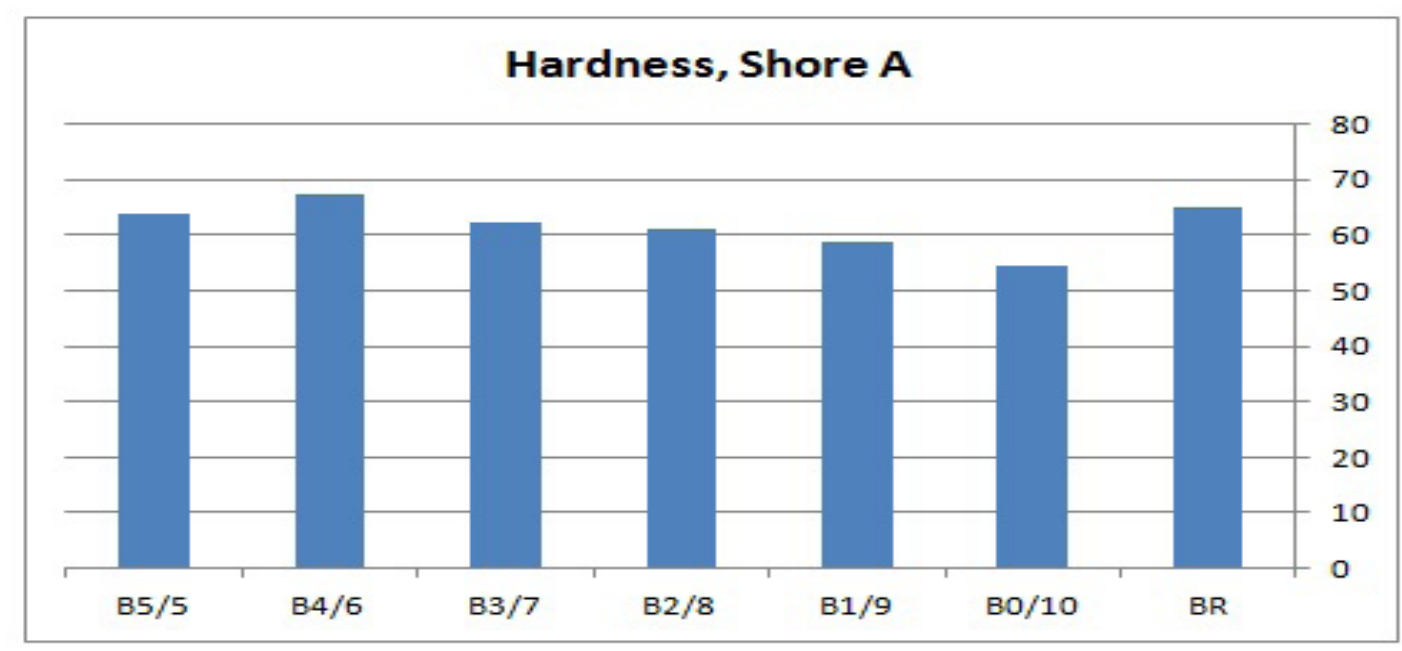

Fig. 4. Hardness shore (A) of rubber nanocomposites with different crumb rubber loadings.

TABLE 3. Hardness Shore (A) and Maximum Tourque Measurements.

\begin{tabular}{lccccccc}
\hline \multicolumn{1}{c}{ Mix } & $\mathbf{B}_{\mathbf{R}}$ & $\mathbf{B}_{\mathbf{0} / \mathbf{0}}$ & $\mathbf{B}_{\mathbf{1 / 9}}$ & $\mathbf{B}_{\mathbf{2} 8}$ & $\mathbf{B}_{\mathbf{3} / 7}$ & $\mathbf{B}_{4 / \mathbf{6}}$ & $\mathbf{B}_{\mathbf{5} / \mathbf{5}}$ \\
\hline Shore A & 65.0 & 54.37 & 58.96 & 61.02 & 62.24 & 67.22 & 64.4 \\
Max. Tourque & 13.91 & 8.64 & 9.19 & 9.74 & 11.77 & 13.44 & 11.99 \\
\hline
\end{tabular}

rubber blend. It seems that at higher percentages of crumb rubber, the nanofiller helps with the crumb in forming a dispersible network within the rubber blend matrix which enhances the rubbers miscibility with each other.

\section{Thermogravimetric Analysis}

High temperature Thermal Analysis (TGA) $\left(50-650^{\circ} \mathrm{C}\right)$ curves for the sample are shown in Table (4a-g). The temperature for the onset of degradation is the temperature at which $10 \%$ degradation occurred $\left(\mathrm{T}_{10}\right)$, the temperature at which 50\% degradation occurred $\left(\mathrm{T}_{50}\right)$ and the temperature at which $90 \%$ degradation occurred $\left(\mathrm{T}_{90}\right)$ were calculated from the TGA data, It was observed that all crumb/natural rubber nanocomposite samples reveal high onset degradation temperature levels showing that the addition of crumb rubber to NR enhances the thermal stability of the crumb/rubber nanocomposites since it showes a steady increase in its values with leveling up the crumb rubber percent. For $\mathrm{T}_{50}$ and $\mathrm{T}_{90}$ temperature values, they both show similar behavior. This increase can be attributed to the increase in the crosslink density. The crosslinking increases the rigidity of the rubber mix, which in turn increases the thermal stability $[29,30]$. This proves that increasing loading of the crumb rubber is responsible for the increase in thermal stability of the rubber nanocomposites with high content of crumb.

\section{Thermal Conductivity}

Since it is a property that associated with materials having low values, i.e., it reflects the thermal insulation behavior. Table 5 represents the results of the thermal conductivity measurements of crumb/NR nanocomposites containing different percent of crumb indicating that thermal insulation values are generally low compared to that of polystyrene, a conventional thermal insulating material, showed thermal insulation values ranging from 0.32 to $0.038 \mathrm{~W} / \mathrm{km}$. Crumb/ NR nanocomposites showed values between 0.105 and $0.147 \mathrm{~W} / \mathrm{km}$ which give a possibility of a potential thermal insulating material which can be used in many industrial applications.

\section{Conclusion}

Regarding the mechanical properties and hardness, the addition of crumb rubber to natural rubber clearly improved the mechanical properties, especially the tensile strength from 3.13 in the control rubber to $6.47 \mathrm{MPa}$ in rubber nanocomposite containing $40 \%$ of crumb rubber, representing an increase of more than $100 \%$.SEM graphs revealed that at higher rubber, representing an increase of more than $100 \%$. SEM graphs revealed that at higher ratios of crumb rubber, the crumb filler forms a dispersible network within the rubber blend matrix which enhanced 
TABLE 4. Thermal properties of natural rubber nanocomposites having different crumb rubber percent.

\begin{tabular}{cccc}
\hline $\mathbf{M i x}$ & $\mathbf{T}_{\mathbf{1 0}},{ }^{\circ} \mathbf{C}$ & $\mathbf{T}_{\mathbf{5 0}},{ }^{\circ} \mathbf{C}$ & $\mathbf{T}_{\mathbf{9 0}},{ }^{\circ} \mathbf{C}$ \\
\hline $\mathrm{B}_{\mathrm{R}}$ & 359 & 397 & 427 \\
$\mathrm{~B}_{0 / 10}$ & 348 & 374 & 308 \\
$\mathrm{~B}_{1 / 9}$ & 352 & 389 & 419 \\
$\mathrm{~B}_{2 / 8}$ & 352 & 389 & 420 \\
$\mathrm{~B}_{3 / 7}$ & 353 & 390 & 424 \\
$\mathrm{~B}_{4 / 6}$ & 356 & 398 & 431 \\
$\mathrm{~B}_{5 / 5}$ & 354 & 392 & 425 \\
\hline
\end{tabular}

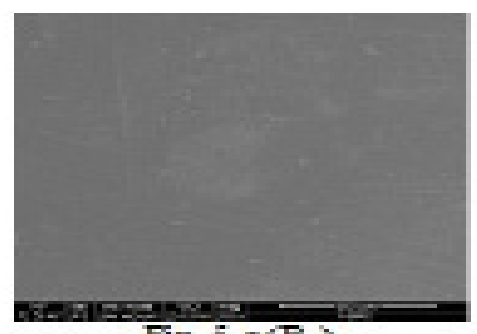

Fis. 3-aris



Fig $3-00000$

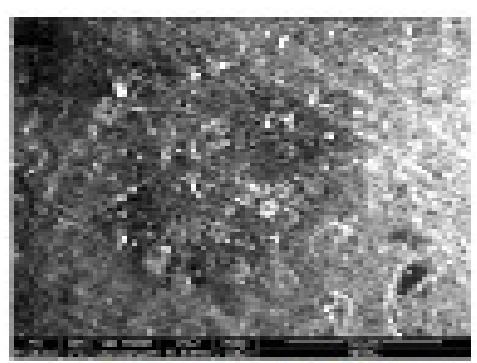

Fig-4a $00 \%$

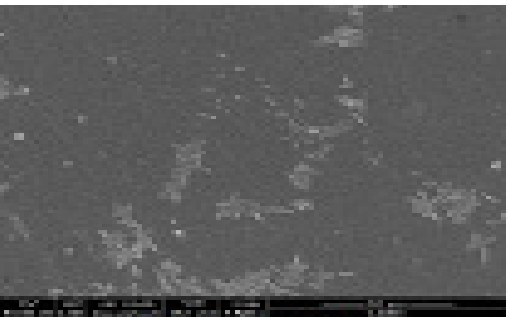

Fig. St modsi

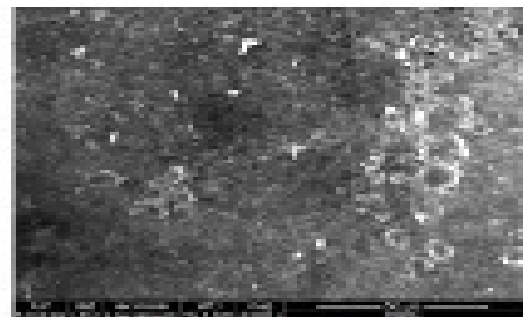

Fig. $5-d(20 \%$

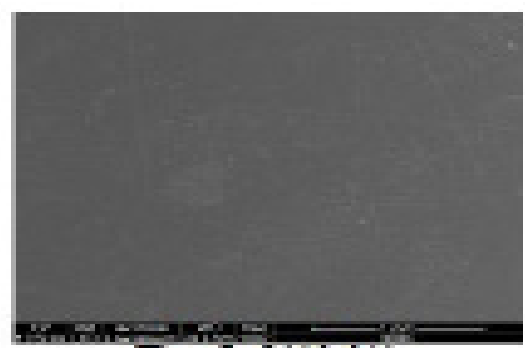

Ftg. 5-f(40)

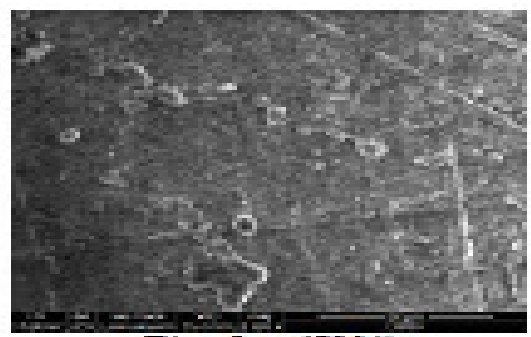

Fig. $5-$ - $60 \%$

Fig. 5. SEM Micrographs of natural rubber nanocomposites having different crumb rubber percentages.

Egypt. J. Chem. 60, No. 6 (2017) 
TABLE 5. Thermal conductivity measurements of B1 and B5, compared to polystyrene.

\begin{tabular}{cc}
\hline Material & Thermal conductivity, W/m K \\
\hline $\mathrm{B}_{\mathrm{R}}$ & 0.137 \\
$\mathrm{~B}_{0 / 10}$ & 0.069 \\
$\mathrm{~B}_{1 / 9}$ & 0.105 \\
$\mathrm{~B}_{2 / 8}$ & 0.123 \\
$\mathrm{~B}_{3 / 7}$ & 0.127 \\
\hline
\end{tabular}

the miscibility between rubber and ingredients. TGA data indicated high stability of all crumb/ NR nanocomposites. Thermal conductivity measurements reflect the incorporation of crumb rubber into natural rubber nanocomposites giving mixes of extremely high values for thermal insulation.

In short, the study showed that crumb rubber may be of beneficial value since it can be mixed with natural rubber composites up to $50 \%$ with improves mechanical properties (100\%). Also, the produced mixes recorded thermal insulating levels high enough to be recommended for constructural thermal insulation purposes, thus giving safer, cleaner mixing and easier processing conditions and in the meantime solves a serious environmental pollution problem.

\section{References}

1. Lee S., Azzam F.O. and Kocher B.S., Oxidative decoupling of scrap rubber. Disclosure ultrasonic depolymerisation of rubber scrap 204 U.S. Patent 5,386,055, Jan 31 (1995).

2. Figovslq O., Beilin D., Blank N., Potapo J. and Chernyshe V., Development of polymer concrete with polybutadiene matrix. Cem Concr Compos 18:437-44 (1996).

3. Segre N.P., Monteiro J.M. and Sposito G., Surface characterization of recycled tire rubber to be used in cement paste matrix. J Colloid Interf Sci 248, 521-3 (2002).

4. Hernandez-Olivares F., Barluenga G., Bollatib M. and Witoszekc B., Static and dynamic behaviour of recycled tyre rubber-filled concrete. Cem Concr Res 32, 1587-96 (2002).

5. Yehia A., Mull M.A., Ismail M.N., Hefny Y.A. and Abdel-Bary E.M., Effect of chemically modified waste rubber powder as a filler in natural rubber vulcanizates. J. Appl. Polym . Sci 93, 30-6 (2004).

Egypt. J. Chem. 60, No. 6 (2017)
6. Dierkes W.K., Rubber recycling. In: Pandalai SG, editor. Recent research developments in macromolecules, Research Signpost, Trivandrum, 7, 265-92 (2003).

7. Kim J.I., Ryu S.H. and Chang Y.W., Mechanical and dynamic mechanical properties of waste rubber powder/HDPE composite. J. Appl. Polym. Sci. 77, 2595-602 (2000).

8. Manchon-Vizuete E., Maci'as-Garci'a A., Nadal Gisbert A., Ferna'ndez-Gonza'lez C. and Go'mezSerrano V., Preparation of mesoporous and macroporous materials from rubber of tyre wastes. Microporous. Mesoporous.Mater 67, 35-41 (2004).

9. Nakason C., Kaesaman A. and Supasanthitikul P., The grafting of maleic anhydride onto natural rubber. Polym Test 23, 35-41 (2004).

10. Isayev A. and Chen J., Continuous ultrasonic devulcanization of vulcanized elastomers. US Patent 5, 258,413, November 2, (1993) .

11. Novotny D.S., Marsh R.L., Masters F.C. and Tally D.N., Microwave devulcanization of rubber. U.S. Patent 4,104, 205, The Goodyear Tire \& Rubber Company (assignee), August 1, (1978).

12. Fliermans C.B. and Wicks G.G., Combination biological and microwave treatments of used rubber products. U.S. Patent 6, 407, 144, Westinghouse Savannah River Company, LLC (assignee), April 4 (2000).

13. Ismail H., Awang M. and Hazizan M., Effect of waste tire dust (WTD) size on the mechanical and morphological properties of polypropylene/ waste tire dust (PP/WTD) blends. Polymer-Plastics Technology and Engineering 45(4), 463-8 (2006).

14. Ismail H., Nordin R. and Noor A., Cure characteristics, tensile properties and swelling behaviour of recycled rubber powder filled natural rubber compounds. Polymer Testing 21(5), 565-9 (2002). 
15. Sakinah Z.A., Ratnam C.T., Chuah A.L. and Yaw T., Effect of Mixing Conditions on the Tensile Properties of Ethylene Vinyl Acetate/Waste Tire Dust (EVA/WTD) Blend. Polymer-Plastics Technology and Engineering 48(11), 1139-42 (2009).

16. Sakinah Z.A.A., Ratnam C.T., Chuah A.L. and Yaw T.C.S., Performance of irradiated and crosslinked ethylene vinyl acetate/waste tire dust blend. Journal of Elastomers and Plastics 43, 239-56 (2011).

17. Sonnier R., Leroy E., Clerc L., Bergeret A. and Lopez-Cuesta J., Polyethylene/ground tyre rubber blends: influence of particle morphology and oxidation on mechanical properties. Polymer Testing 26(2), 274-81 (2007).

18. Sonnier R., Leroy E., Clerc L., Bergeret A. and Lopez-Cuesta J., Polyethylene/ground tyre rubber blends: influence of particle morphology and oxidation on mechanical properties. Polymer Testing 26(2), 274-81 (2007).

19. Darwish N., Abd El-Aal N. and Abd El-Megeed A., Effect of addition of HDPE and LDPE on rheological, mechanical, elastic and compatibility behavior of SBR/NBR rubber blend system. Polymer-Plastics Technology and Engineering 46(4), 345-52 (2007).

20. Zulkepli N.N., Ismail H. and Rashid A., Effects of different particle sizes of recycled acrylonitrilebutadiene rubber and its blend ratios on mechanical and morphological properties and curing characteristics of $\mathrm{SBR} / \mathrm{NBRr}$ blends. Iranian Polymer Journal 18(2), 1-10 (2009).

21. Colom X., Carrillo F. and Canavate J., Composites reinforced with reused tyres: surface oxidant treatment to improve the interfacial compatibility. Composites Part A: Applied Science and Manufacturing 38(1), 44-50 (2007).
22. Mingchao Luo, Xiaoxue Liao, Shuangquan Liao and Yanfang Zhao, Journal of applied Polymer Science, 129, 2313-2320, (2013).

23. Ratnam C. T., Ramarad S., Khalid M. and Noraini, effect of pre-irradiation of waste tire dust on the properties of ethylene vinyl acetate/waste tire dust blend (EVA/WTD) blends. Journal of Composites and Biodegradable Polymers 1, 16-22 (2013).

24. Movahed S.O., Ansarifar A. and Mirzaie F., Journal of Applied Polymer Science, 132, 41512 (2015).

25. ASTM D 3182-07 "Standard Practice for Rubber Materials, Equipment and Procedures for Mixing Standard Compounds and Preparing Standard Vulcanized Sheets".

26. ASTM D 2084-07 "Test Standard Methods for Rubber Property-Vulacization Using Oscillating Disk Cure Meter".

27. ASTM D 412-06 "Standard Test Method for Vulcanized Rubber and Thermoplastic ElastomersTension".

28. ASTM D 2240-05 "Standard Test Method for Rubber Property Durometer Hardness".

29. ASTM D 412-06 "Standard Test Method for Vulcanized Rubber and Thermoplastic ElastomersTension".

27. Maity M., Khatua B.B., Das C.K., Effect of processing on the thermal stability of the blends based on polyurethane: part IV. Polym. Degrad. Stab. 72, 499 (2000).

29. Gann R.G., Dipert R.A., Drews M.J., Flammability. In: Kroschwitz, J.I. (ed) Encyclopedia of Polymer Science and Engineering, $2^{\text {nd }}$ edn. John Wiley \& Sons, Inc., New York 7, 154-210 (1985).

( Received 12/8/2017; accepted 14/12/2017) 


\section{دراسة عن دور فتات المطاط فى الخواص الحرارية والميكانيكية لمتراكبات المطاط الطبيعى النانونية

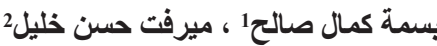

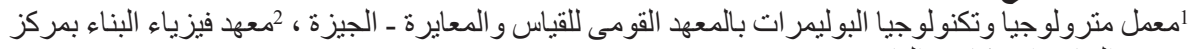 بحوث البناء و الإسكان ـ القاهرة ـ مصر ل.}

يعتبر فتات المطاط المطاطي سلسلة من النفايات الخطيرة التي تسبب التلوث البيئي. و تستهلك هذه المشكلة

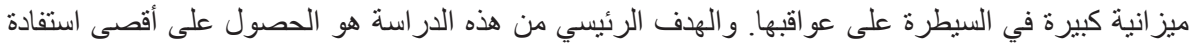

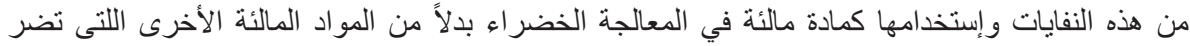

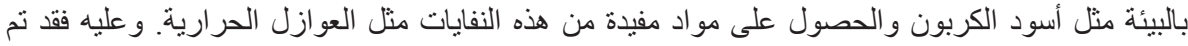

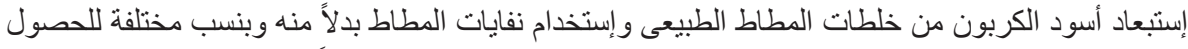



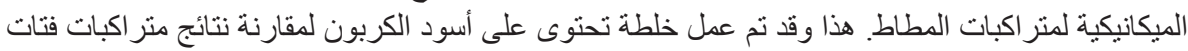
النفايات/المطاط الطبيعى. وتم فحص هذه الخلطات عن طريق الميكروسكوب الماسح الإلكتروني (SEM) و

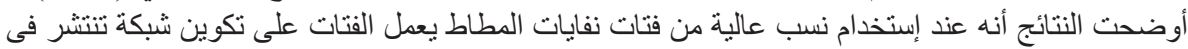

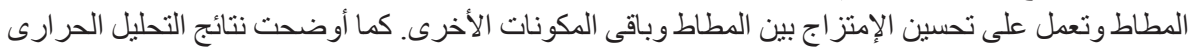

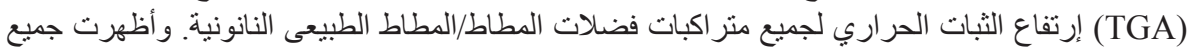

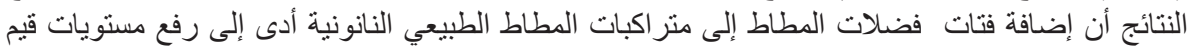

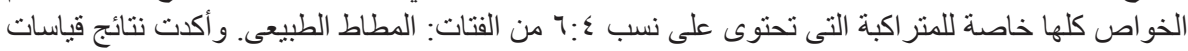

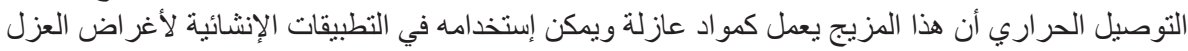
الحرارى. 